\title{
POLY (N-VINYLCARBAZOLE) AND ( $\alpha$-POLMETHYLSTYRENE) BASED SEMI INTERPENETRATING POLYMER NETWORK: SYNTHESIS AND CHARACTERIZATION
}

\author{
Dayanand Mishra*, Meet Kamal \\ Department of Chemistry, Christ Church Degree College, Kanpur, Uttar Pradesh, India \\ *Corresponding author: dayanandmishra124@gmail.com
}

\begin{abstract}
A series of interpenetrating polymer network (IPN) based on poly(N-vinylcarbazole) and poly $(\alpha$-methylstyrene) were synthesized using benzoylperoxide (BPO) as initiator and divinyl benzene as crosslinker. The IPNs were characterized using infrared spectroscopic technique, differential scanning calorimetric analysis, thermal gravimetric analysis and scanning electron microscope techniques. FTIR spectra of the synthesized polymeric network revealed the band positions for poly(N-vinylcarbazole), at $2923 \mathrm{~cm}^{-1}, 1600 \mathrm{~cm}^{-1}$ and $1629 \mathrm{~cm}^{-1}$, and for poly( $\alpha$-methylstyrene) at $3019 \mathrm{~cm}^{-1}, 1484$ $\mathrm{cm}^{-1}, 707 \mathrm{~cm}^{-1}$ and $1451 \mathrm{~cm}^{-1}$. The relatively shortened peak value $\left(1595 \mathrm{~cm}^{-1} \mathrm{CH}_{-} \mathrm{CH}_{2^{-}}\right)$of vinyl group in poly $(\alpha-$ methylsytrene) justify the disappearance of double bond which is a clear indication of bonding between the two polymer networks leading to IPN formation. The differential scanning calorimetry (DSC) graph showed glass transition temperature $\left(\mathrm{T}_{\mathrm{g}}\right)$ at $449^{\circ} \mathrm{C}$, which indicate crystalline nature of synthesized IPN. Thermogravimetric analysis (TGA) graph showed thermal stability of IPN upto $395^{\circ} \mathrm{C}$. Fluorescence spectra of IPN at the visual range near 450 nanometer also predicts its good optical properties. The SEM image showed a transparent and dual morphology of the synthesized polymeric network. The properties like percentage swelling, average molecular weight (Mc) between crosslinker are in direct function of initiator (benzoyl peroxide) and poly( $\mathrm{N}$-vinyl carbazole) but inverse function of monomer $(\alpha$ methylsytrene) and crosslinker (divinyl benzene).
\end{abstract}

Keywords: Swelling, Morphology, Network, Crosslinker, Fluorescence.

\section{INTRODUCTION}

In the present polymer world, interpenetrating polymer network is defined as a combination of two or more crosslinked polymers in a network with at least one of the system synthesized or crosslinked in the presence of another. These reactions may be simultaneous. Carbazole based interpenetrating polymer networks are of considerable scientific and industrial interest due to their attractive approach of combining to different properties easily and bears good optical properties also. Among carbazole polymers, a central place is reserved for poly(N-vinyl carbozole) because it is easily synthesized. This is an applicable approach and has been employed by a number of scientists to describe novel IPN systems for commercial applications. Investigators discussed their view regarding enhancement of IPN study. Millar [1] was the first person to use the concept of 'IPN' and prepared from identical styrene - divinyl benzene production with polymer networks. A mass of studies are reported in the literature about the IPNs of PUI. The first reported work is by Sperling et al. [2].
Ekici and co-worker [3] synthesized a special IPN, carrying drug release properties. They worked out to prepare IPN hydrogel of chitosan poly (N-vinyl pyrrolidone) and poly(acrylic acid) with $\mathrm{N}, \mathrm{N}$ methylene bisacrylamide (MBA). This was a unique IPN hydrogel which holds better swelling properties along with upgraded thermal and mechanical properties. The individual polymer is linked together by crosslinking but not chemically linked [4]. Zahao and co-workers [5] reported synthesis of elastomers and gel from IPN. Synthesis and characterization of interpenetrating polymer network poly(glycidyl methacrylate) and acrylamide using selenenium ylide as an initiator and divinyl benzene as crosslinker was done by Anamika Singh [6]. Peerasak et al. [7] synthesized styrene and 4vinyl pyridine with poly(ethylene tetraphthalate) using benzoyl peroxide. Prashantha et al. [8] formed polyurethane epoxy IPNs and widely applied to fibers, foams, coating, leathers and other applications. Kyriakos et al. [9] described versatile synthetic methodology that leads to the generation of nonconjugated 3D 
luminescent semi interpenetrating aliphatic network. Tamrin and coworker [10] synthesized IPN from composite base on poly composite polyurethane-natural rubber assisted montmorillonite as Filler. It showed the improve mechanics, morphology and thermal properties of IPN. Netu et al. [11] studied photoluminescence spectroscopy property as an important tool which has been used $\left(\mathrm{TiO}_{2} / \mathrm{SnO}_{2}\right)$ sensing of gas. Meet and coworker [12] described conductivity behaviour of semi IPN of fullerene based polyacrylonitrile and polyaniline. Petra et al. [13] reported synthesis of semi IPN by ring opening polymerization of $\varepsilon$-caprolactone and the poly (styrene-co-divinyl benzene) which has a pronounced effect on the morphology of obtained polystyrene frame works. Further, Ruima et al. [14] synthesized IPN based on Trisocyanate-terminated and modified poly (urethene-imide) with superior mechanical properties.

A lot of work has been carried on silicon polymers and vinyl monomers. But synthesis of vinyl carbazole based IPN is still scare. Therefore, the present study emphasized on synthesis of IPN based on interaction of poly(N-vinyl carbazole) and poly $(\alpha$-methyl styrene). The aim of the research work is to fabricate a network system to describe various physiochemical and thermal properties. The vinyl monomeric repeating units of $\alpha$-methyl styrene provides a great sense of interpenetration where as poly(N-vinylcarbozole) is a temperature resistant thermoplastic polymer.

\section{MATERIAL AND METHODS}

N-vinylcarbazole (NVK 98\%) (Sigma Aldrich) and Benzoyl peroxide (Merck 98\%) was recrystallized thrice from methanol. Divinyl benzene, solvents (Merck) were used as received. $\alpha$-methyl styrene (98\%) (Kemphasol) was purified by recrystallization from methanol. All other material were used without further purification.

\subsection{Preparation of poly ( $\mathrm{N}$-vinylcarbozole)}

$\mathrm{N}$-vinylcarbazole (19.3 gm or 0.1 mole) was placed in a conical flask $(250 \mathrm{ml})$. Benzolyl peroxide $(0.5 \mathrm{~g})$ was dissolved in $100 \mathrm{ml}$ acetonitrile and added to the flask which was heated at $70^{\circ} \mathrm{C}$ over a 4 hours period. The polymer was precipitated by methyl alcohol and washed with acetone and dried under constant weight.

\subsection{Synthesis of IPN}

Interpenetrating polymer network of poly(Nvinylcarbazole) and poly( $\alpha$-methyl styrene) were synthesized by systematic variation of concentration of poly ( $\mathrm{N}$-vinylcarbazole) and $\alpha$-methyl styrene using benzoyl peroxide as initiator and divinyl benzene as crosslinking agent in toluene as solvent. The system was kept on water bath for 3 hours at $70^{\circ} \mathrm{C}$ under an inert atmosphere. The IPNs was obtained after evaporating the solvent. The IPNs formed were precipitated in methanol and vacuum dried to constant weight.

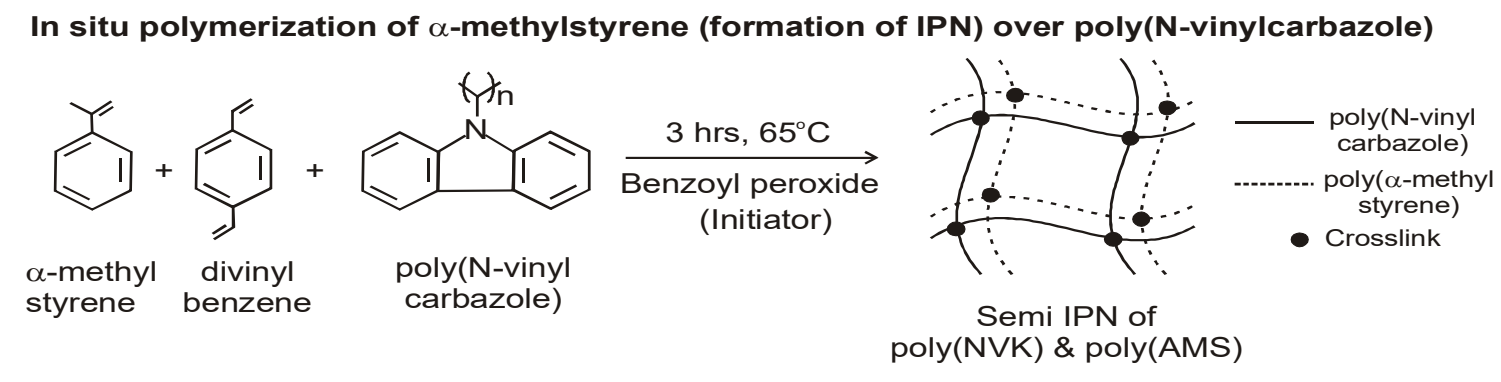

\section{Scheme 1: Synthesis of IPN based on poly(N-vinylcarbazole) and $\alpha$-methylstyren}

\subsection{Characterization of IPN}

The IPNs were formulated and characterized using spectroscopic technique, thermal techniques and scanning electron microscopic techniques.

\subsubsection{FTIR Measurement}

The IR spectra of synthesized IPNs were recorded by a Perkin-Elmer spectrum version 10-03-06 instrument using the dry $\mathrm{KBr}$ at room temperature. The IR spectrum was carried out at wavelength 500$4000 \mathrm{~cm}^{-1}$.

\subsubsection{Thermal analysis}

Thermal properties were analyzed by Simultaneous DSC/TGA technique on the instrument model SDTQ 600 V 20.9 Build 20. All spectra were recorded under nitrogen atmosphere upto $800^{\circ} \mathrm{C}$ using programmed rate of $10^{\circ} \mathrm{C} /$ minute.

\subsubsection{Fluorescent characterization}

The fluorescence emission and excitation spectrum of IPNs were recorded on a spectrofluorimeter (Fluorolog 3, Model FL 3-22). 


\subsubsection{SEM Morphology}

The morphology images of the synthesized IPNs have been studied by the SEM technique with varying magnification. The IPN samples were Gold Sputter coated carried out using model JEOLJ SM $840 \AA$ scanning electron micrsoscope (SEM).

\subsubsection{Swelling measurements}

Swelling behaviour of IPNs sample were calculated by soaking the sample in $10 \mathrm{ml}$ of different solvents such as dimethylformamide (DMF), dimethyl sulphoxide (DMSO), benzene or toluene until an equilibrium weight was achieved $(\sim 24 \mathrm{hrs})$. The solvent was removed by heating the sample to $60^{\circ} \mathrm{C}$ under vaccum until equilibrium was achieved. The weight of the swollen film in each solvent was recorded at different time. The swollen percentage was calculated according to the following relationship [15].

$$
\% \text { Swelling }=\left(\frac{W_{s}-W_{d}}{W_{d}}\right) \times 100
$$

where $\mathrm{W}_{\mathrm{s}}=$ weight of swollen IPN and $\mathrm{W}_{\mathrm{d}}=$ Weight of dry IPN.

\subsubsection{Calculation of percentage extractable materials}

The uncrosslinked component of IPN was removed with the help of Soxhlet extractor using dimethyl sulphoxide (DMSO) as solvent, otherwise no reproducible results were obtained. The percentage extractable material was calculated using the following formula:

$$
\% \text { Extractable material }=\left(\frac{W_{b}-W_{a}}{W_{a}}\right) \times 100
$$

where $\mathrm{W}_{\mathrm{b}}=$ Weight of IPN before extraction and $\mathrm{W}_{\mathrm{a}}=$ Weight of IPN after extraction.

\subsubsection{Crosslink density (1/Mc)}

The IPN sample was taken and its crosslink density $(1 / \mathrm{Mc})$ of the network was determined by using the swelling data of IPN in DMF with help of Flory-Rehner equation $[16,17]$.

$$
\frac{1}{M_{c}}=-\frac{\left(\operatorname{In}\left(1-V_{p}\right)+V_{p}+X_{12} V_{p}^{2}\right)}{p_{1}\left(V_{p}^{1 / 3}-V_{p} / 2\right)}
$$

where, $\mathrm{M}_{\mathrm{c}}=$ average molecular weight of network between crosslinks, $p=$ density of the network, $V_{1}=$ molar volume of solvent, and $\mathrm{V}_{\mathrm{p}}=$ volume fraction of polymer in swollen gel, $\mathrm{X}_{12}=$ polymer solvent interaction parameter, calculated by the expression [18].

$$
\mathrm{X}_{12}=\mathrm{B}+\frac{\mathrm{V}_{1}\left(\delta_{\mathrm{p}}-\delta_{\mathrm{s}}\right)^{2}}{\mathrm{RT}}
$$

where $\delta_{\mathrm{p}}$ and $\delta_{\mathrm{s}}=$ solubility parameters of polymer and swelling solvent, respectively, and B = lattice constant, the value of which is taken as 0.34 .

\section{RESULTS AND DISCUSSION}

\subsection{FTIR spectral analysis}

The structural analysis of polymeric network was studied by FTIR spectroscopic technique. We have examined the detailed vibrational FTIR spectra of the synthesized IPN. FTIR study for pure poly(N-vinyl carbazole) (PNVK) (Fig. 1) revealed, peaks at 2964 $\mathrm{cm}^{-1}$ (C-H a symmetric), $2927 \mathrm{~cm}^{-1}$ (for C-H symmetric stretching), $1595 \mathrm{~cm}^{-1}$ (for $\mathrm{C}=\mathrm{C}$ stretching in vinylidene) and $1639 \mathrm{~cm}^{-1}$ ( for $\mathrm{C}=\mathrm{C}$ stretching in aromatic ring) and for poly( $\alpha$-methyl styrene) it depicted peaks at $3000 \mathrm{~cm}^{-1}$ (stretching vibrations), $1490 \mathrm{~cm}^{-1}$ (for $\mathrm{C}-\mathrm{C}$ vibrations), $3010 \mathrm{~cm}^{-1}$ (for $\mathrm{C}-\mathrm{H}$ stretching vibrations), $699 \mathrm{~cm}^{-1}$ (benzene ring $\mathrm{C}=\mathrm{C}$ bending) and $1444 \mathrm{~cm}^{-1}$ (for bending vibrations of $\mathrm{C}-\mathrm{H}$ bond of $-\mathrm{CH}_{3}$ group). While IR spectra for the synthesized IPN (Fig. 3) revealed the peaks for poly(Nvinyl carbazole) at $2923 \mathrm{~cm}^{-1}$ (C-H asymmetric stretching), $1600 \mathrm{~cm}^{-1}(\mathrm{C}=\mathrm{C}$ stretching in vinylidene $)$ and $1629 \mathrm{~cm}^{-1}(\mathrm{C}=\mathrm{C}$ stretching in aromatic ring $)$ and for poly $(\alpha$-methyl styrene) it is depicted peaks at 3019 $\mathrm{cm}^{-1}$ (stretching vibration), $1484 \mathrm{~cm}^{-1}$ (for C-H vibration), $3019 \mathrm{~cm}^{-1}$ (for $\mathrm{C}-\mathrm{H}$ stretching vibration), $707 \mathrm{~cm}^{-1}$ (for benzene ring $\mathrm{C}=\mathrm{C}$ bonding) and 1451 $\mathrm{cm}^{-1}$ (for bending vibration of $\mathrm{C}-\mathrm{H}$ bond of $-\mathrm{CH}_{3}$ group). For companion FTIR spectra of $\alpha$-methyl styrene also been depicted is Fig. 2.

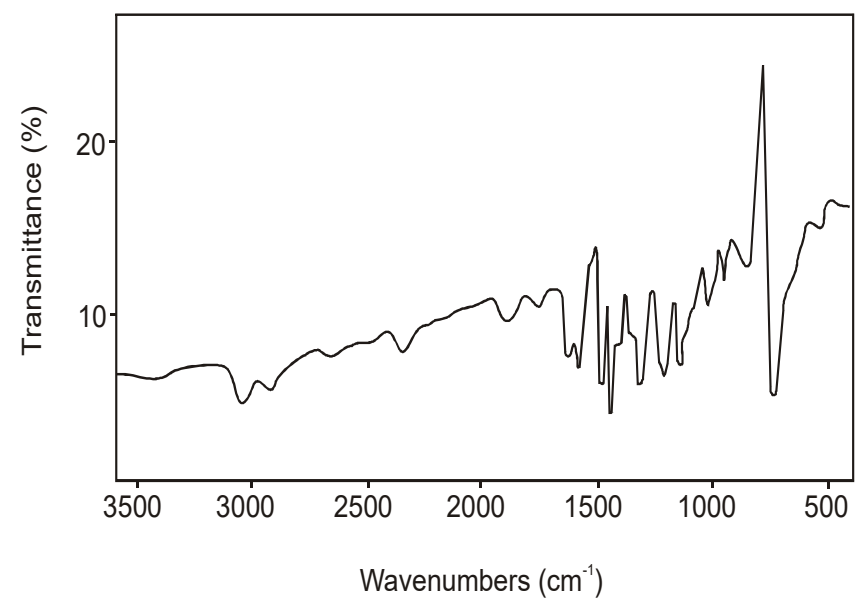

Fig. 1: IR spectra of poly(N-vinylcarbazole) 
Moreover, the shortened and relatively broadened peak value $\left(1595 \mathrm{~cm}^{-1},-\mathrm{CH}-\mathrm{CH}_{2}-\right)$ of vinyl group in poly $(\alpha-$ methyl styrene) justify the disappearance of the double bond. This band shifting revealed the interpenetration of poly( $\alpha$-methylstyrene $)$ is poly $(\mathrm{N}$-vinylcarbazole) matrix.

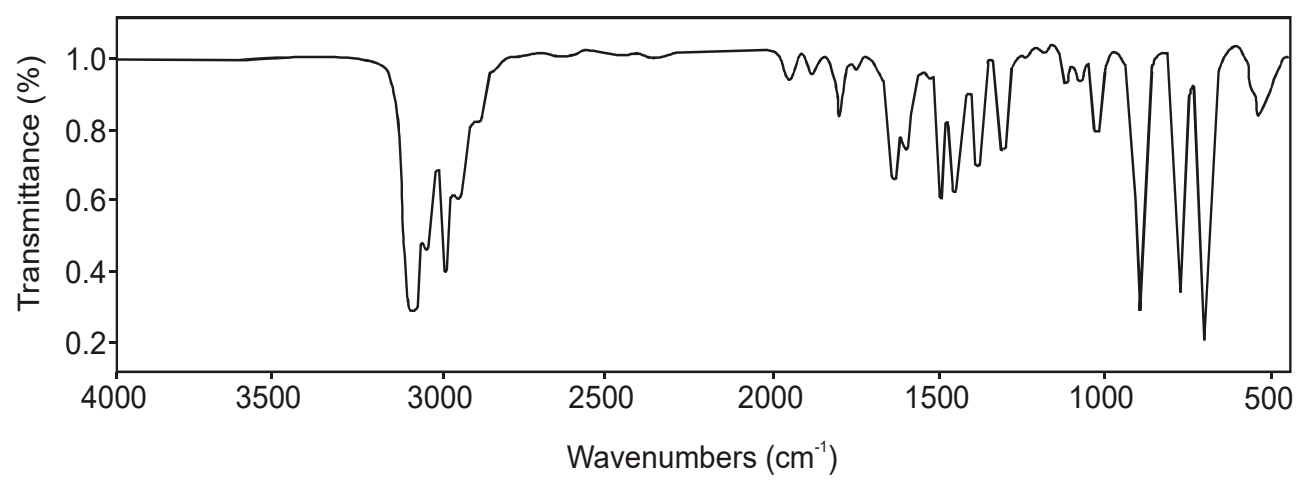

Fig. 2: IR spectra of $\alpha$-methylstyrene

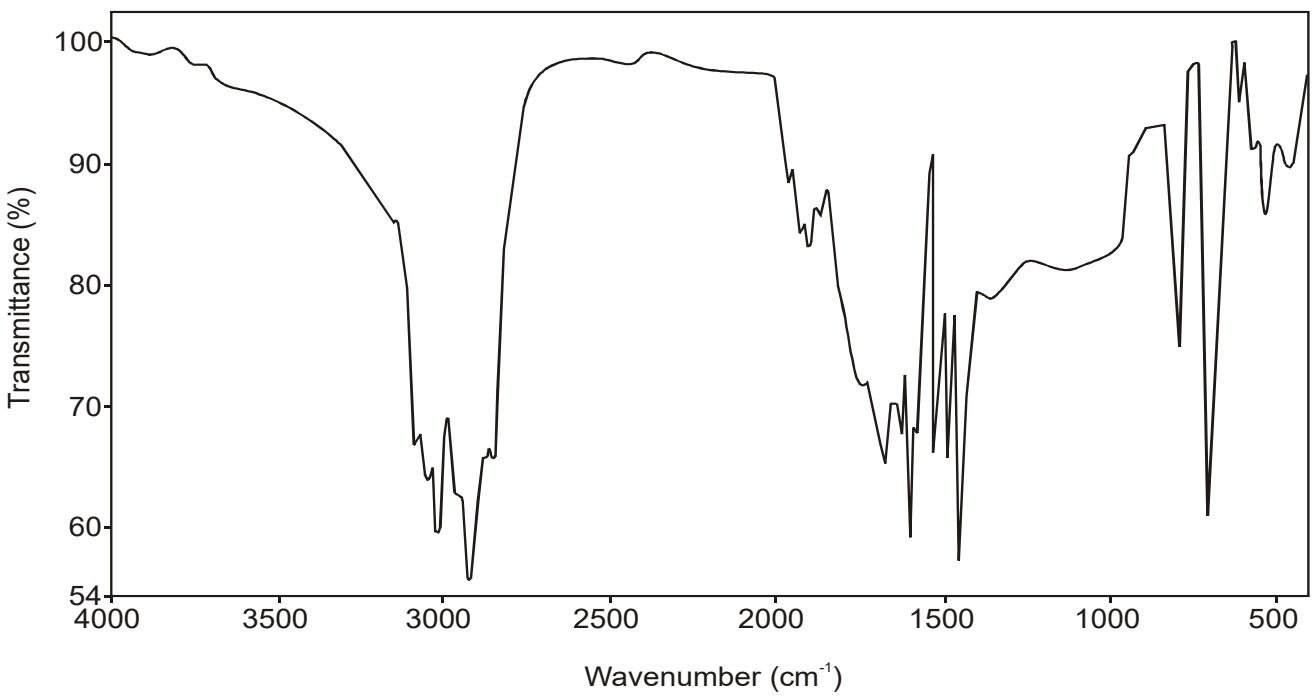

Fig. 3: IR spectra of IPN

\subsection{Thermal Analysis}

\subsubsection{DSC}

DSC thermogram of IPN sample contain crystalline peak ( $\mathrm{Tg}$ ) at $447^{\circ} \mathrm{C}$ (Fig.4), which is in higher than $\mathrm{Tg}$ of poly $(\alpha$-methyl styrene $)\left(435^{\circ} \mathrm{C}\right)$ and poly $(\mathrm{N}$-vinyl carbozole $)\left(225^{\circ} \mathrm{C}\right)$. It might be caused by high crosslinking density in the IPN. It is an evidence of strong restricted chain mobility. N-vinylcarbozole macromolecules are entangled or even covalently bonded to crosslink. Poly $(\alpha$-methylstyrene) (result of interpenetration). Poly(N-vinyl carbozole) has stiff backbone length which provides stiffness to polymer network and poly( $\alpha$-methylstyrene) has comparatively thermal resistant backbone and participate in properties of IPN.

\subsection{2. $T G A$}

Thermal stability of the IPN was studied by TGA from 25 to $800^{\circ} \mathrm{C}$. It displaced degradation upon gradual heating of the sample during the entire thermogram from Fig.5. This shows that initial thermal decomposition at $390^{\circ} \mathrm{C}$. The thermal decomposition pattern of IPN ranges between the poly(Nvinylcarbozole) and poly( $\alpha$-methylstyrene). This result indicates the incorporation of $\alpha$-methylstyrene unit in the polymer network.

\subsubsection{Fluorescent characterization}

Fluorescence emission spectra of polymeric network (Fig.6) reveal fluorescent excitation and emission spectra of the synthesized IPN. The fluorescent 
excitation and emission spectra of IPN nanosheets depict that the polymeric network exhibit analogous excitation and emission. The emission spectra reveal a broad peak centered at about $450 \mathrm{~nm}$, owing to $n \rightarrow \pi *$ electronic transition found in polymeric network.
Emission spectra generated by radioactive decay of excitations exhibit a maximal peak at $450 \mathrm{~nm}$, suggesting that the synthesized IPN nanosheets are typically high intensity blue light emitting materials.

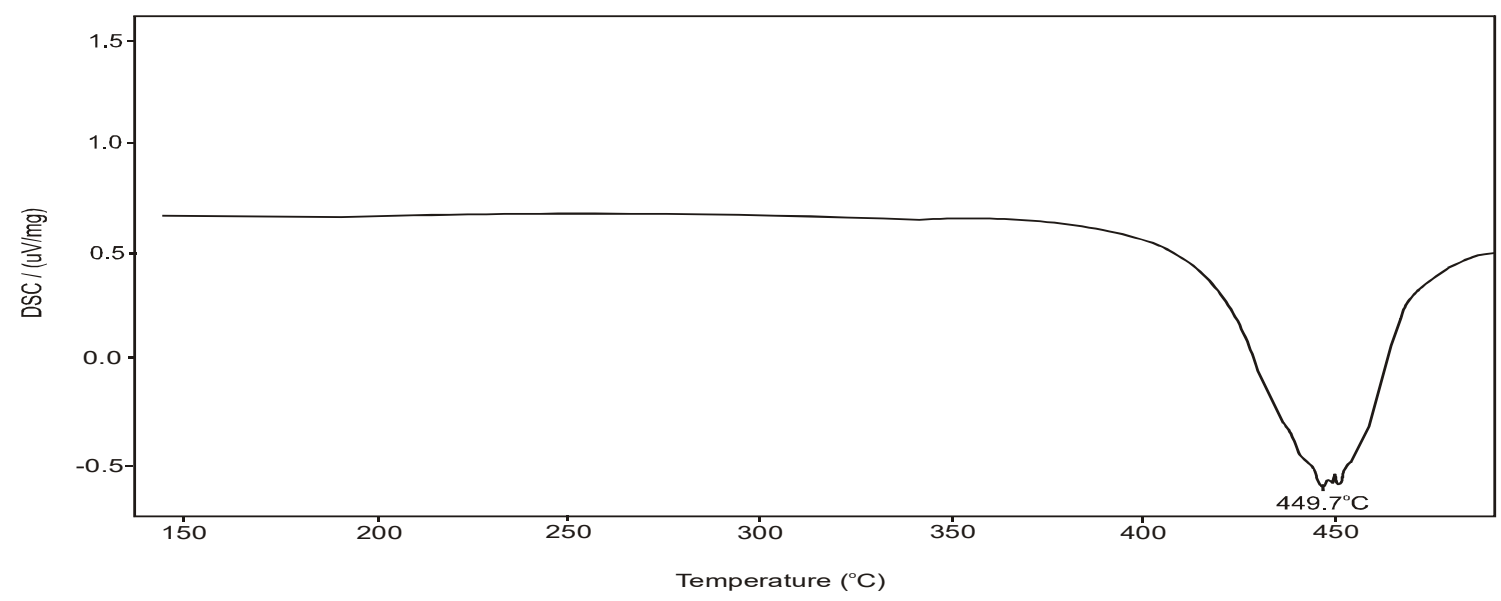

Fig. 4: DSC thermogram of IPN

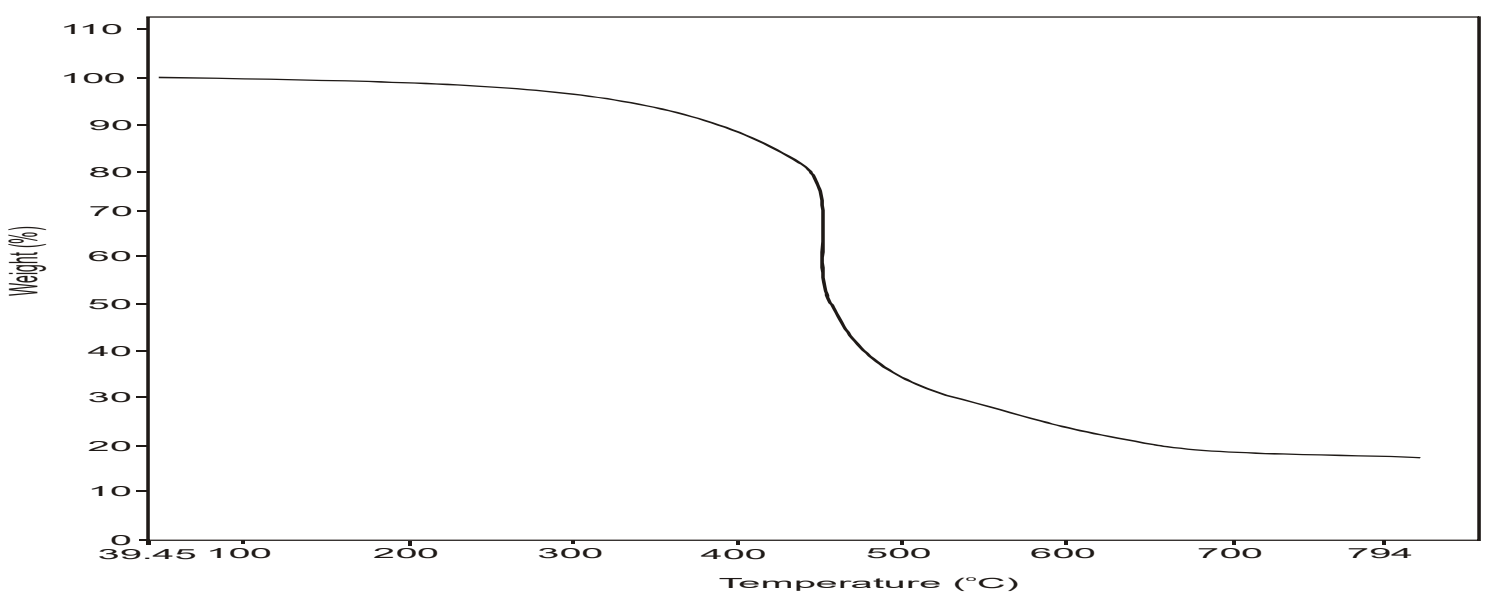

Fig. 5: TGA curve of IPN

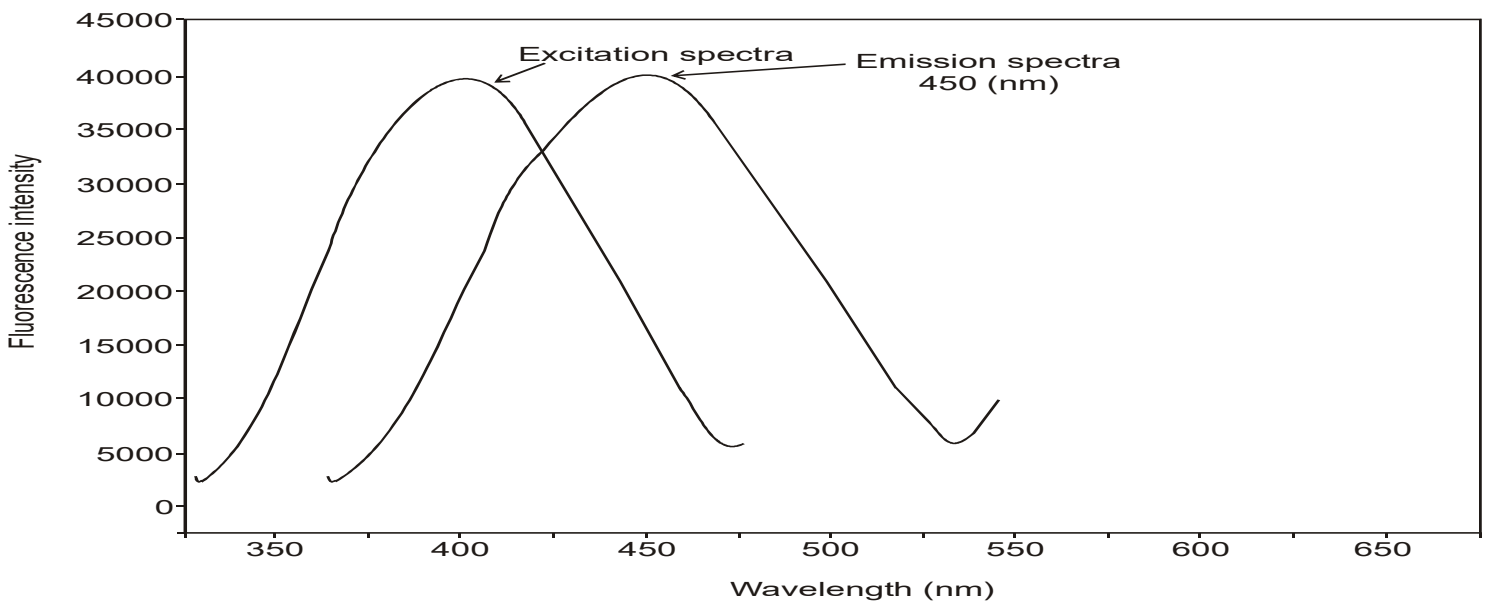

Fig. 6: Fluorescent excitation and emission spectra of IPN 


\subsubsection{Morphology}

The micro structure of interpenetrating network of poly ( $\mathrm{N}$-vinylcarbozole) and poly $(\alpha$-methylstyrene) is observed. The SEM images indicate dual phase morphology of synthesized IPN (Fig. 7). The network
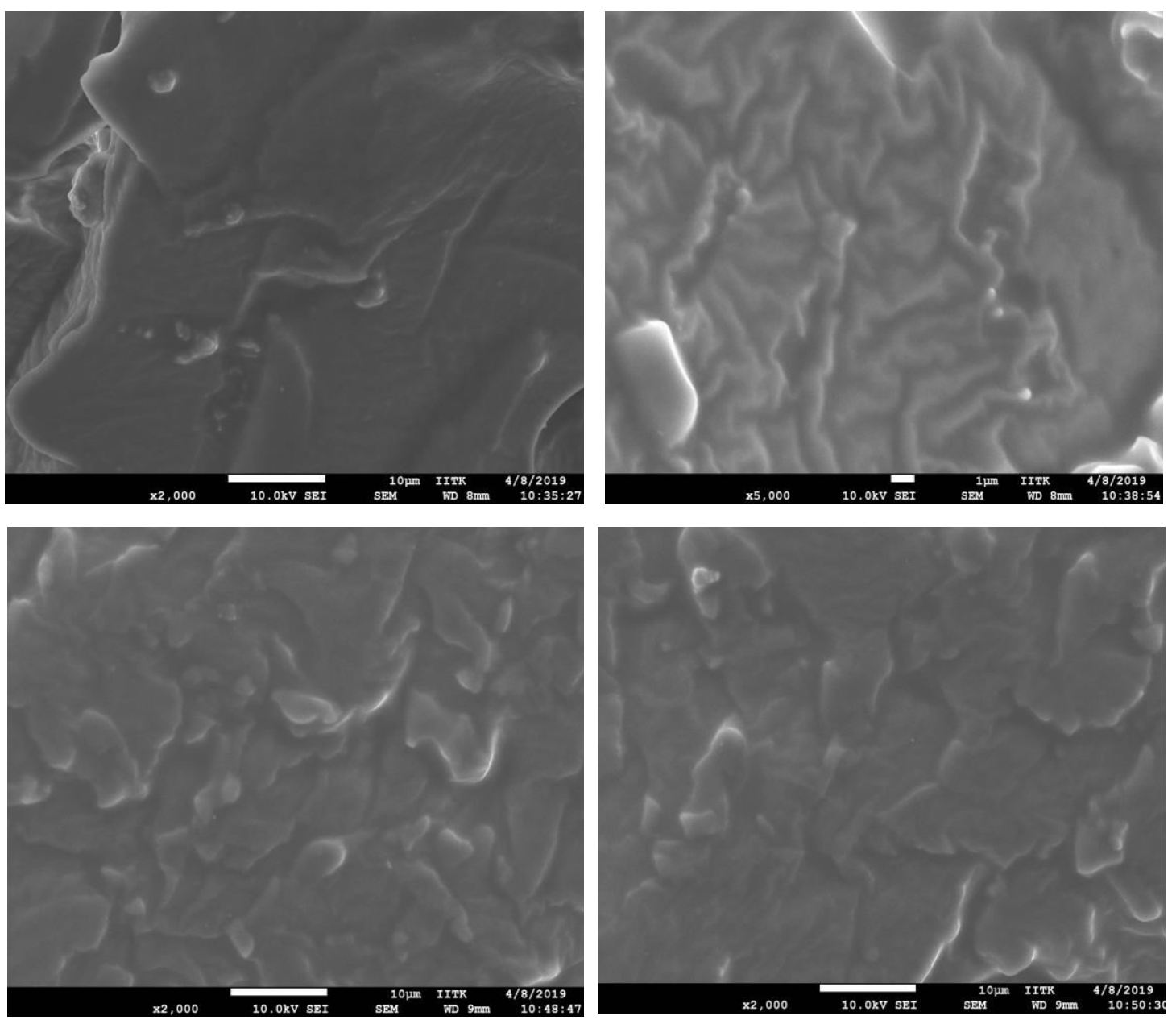

Fig. 7: SEM photograph of IPN

\subsubsection{Effect of composition}

The swelling behaviour could be envisaged from Table 1 which represents the effect of various solvent in swelling and percentage of extractable material on the different physical and chemical properties of IPN. The study of effect of composition of poly(N-vinylcarbazole) and poly $(\alpha$-methylstyrene $)$ shows as trend, since an increase in concentration of poly $(\alpha$-methylstyrene $)$ for poly $(\mathrm{N}$ vinylcarbozole) result in increased swelling and molecular weight (Mc) (Table 2). It shows that poly(N-vinylcarbozole) restricts crosslinking of poly $(\alpha$ methylstyrene). As the concentration of $\operatorname{poly}(\alpha$ methylstyrene) increases, interpenetration of poly( $\mathrm{N}$ vinylcarbazole) also increases. The crystallinity of structure is diversified, which indicate sample heterogeneity of solution used for film preparation. It means phase separation has occurred just after solvent evaporation which is clearly distinguished. 


\subsubsection{Effect of initiator (BPO)}

The variation and effect of BPO concentration over swelling and molecular weight (Mc) of IPN is shown in Table 4. It is clear that both swelling and molecular weight increases with increase molar concentration of benzoylperoxide.

\subsubsection{Effect of crosslinker (DVB)}

Table 5 indicates that as the concentration of crosslinker DVB increases, the value of crosslink density and percentage swelling decreases. The reason is that an increase of concentration of DVB increases the crosslinking between the two polymeric networks which results decreased swelling and $\mathrm{M}_{\mathrm{c}^{\prime}}$. It is interesting to note that concentration increase in DVB enhances the crosslinking in the polymeric network and hence depress the chain mobility. This ultimately increases the glass transition temperature. The IPN does not dissolve, but swells in DMF. It is an evidence for crosslinking between two components.

Table 1: Percentage swelling of IPN in different solvent and extractable material (\%)

\begin{tabular}{cccccc}
\hline Sample used & DMSO $(\%)$ & Benzene $(\%)$ & Toluene $(\%)$ & DMF $(\%)$ & Extractable Material $(\%)$ \\
\hline IPN 1 & 48 & 27 & 41 & 33 & 13.6 \\
\hline IPN 2 & 60 & 36 & 49 & 35 & 15.2 \\
\hline IPN 3 & 71 & 40 & 52 & 55 & 16.0 \\
\hline IPN 4 & 82 & 42 & 56 & 52 & 26.8 \\
\hline IPN 5 & 42 & 21 & 37 & 25 & 13.6 \\
\hline IPN 6 & 39 & 17 & 32 & 22 & 14.4 \\
\hline IPN 7 & 40 & 15 & 28 & 35 & 36.2 \\
\hline IPN 8 & 54 & 42 & 39 & 39 & 24.1 \\
\hline IPN 9 & 61 & 25 & 34 & 33 & 13.4 \\
\hline IPN 10 & 67 & 23 & 32 & 27 & 12.0 \\
\hline IPN 11 & 38 & 26 & 48 & 41 & 11.5 \\
\hline IPN 12 & 31 & 23 & 25 & 36 & 12.8 \\
\hline IPN 13 & 22 & 11 & 25 & 23 &
\end{tabular}

Table 2: Effect of variation poly(N-vinylcarbozole) on IPN properties

\begin{tabular}{ccccc}
\hline Sample & Poly(NVK) $\left(\mathrm{mol} \mathrm{l}^{-1} \times 1^{-3}\right)$ & Yield & Swelling (\%) in DMSO & M $_{\mathrm{c}}$ in DMF \\
\hline IPN 1 & 76.9 & 1.157 & 48 & 160 \\
\hline IPN 2 & 11.5 & 1.386 & 60 & 175 \\
\hline IPN 3 & 153.8 & 1.722 & 71 & 181 \\
\hline IPN 4 & 192.3 & 1.850 & 82 & 189 \\
\hline
\end{tabular}

Table 3: Effect of variation of $\alpha$-methylstyrene on IPN properties

\begin{tabular}{ccccc}
\hline Sample & $\alpha$-methylstyrene $\left(\mathrm{mol} \mathrm{l}^{-1} \times 10^{-3}\right)$ & Yield & Swelling (\%) in DMSO & $M_{\mathrm{c}}$ in DMF \\
\hline IPN 1 & 62 & 1.157 & 48 & 160 \\
\hline IPN 5 & 93.1 & 1.138 & 42 & 152 \\
\hline IPN 6 & 124.1 & 0.850 & 39 & 149 \\
\hline IPN 7 & 155.2 & 0.453 & 40 & 136 \\
\hline
\end{tabular}

Table 4: Effect of variation of (BPO) on IPN properties

\begin{tabular}{ccccc}
\hline Sample & $\mathrm{BPO}\left(\times 10^{-2} \mathrm{~mol} \mathrm{l}^{-1}\right)$ & Yield & Swelling (\%) in DMSO & $\mathrm{M}_{\mathrm{c}}$ in DMF \\
\hline IPN 1 & 0.412 & 1.157 & 48 & 160 \\
\hline IPN 8 & 0.619 & 1.750 & 54 & 175 \\
\hline IPN 9 & 0.825 & 1.468 & 61 & 183 \\
\hline IPN 10 & 1.030 & 2.156 & 67 & 189 \\
\hline
\end{tabular}


Table 5: Effect of variation of (DVB) on IPN properties

\begin{tabular}{ccccc}
\hline Sample & DVB $\left(\mathrm{mol} \mathrm{l}^{-1}\right)$ & Yield & Swelling $(\%)$ in DMSO & M $_{\mathrm{c}}$ in DMF \\
\hline IPN 1 & 0.70 & 1.157 & 48 & 160 \\
\hline IPN 11 & 1.05 & 1.550 & 38 & 149 \\
\hline IPN 12 & 1.40 & 1.680 & 31 & 136 \\
\hline IPN 13 & 1.70 & 2.130 & 22 & 123 \\
\hline
\end{tabular}

\section{CONCLUSION}

The present work has given rise to the formation of tough and strong conducting polymer network of poly(N-vinylcarbazole) and $\alpha$-methylstyrene, which reveals a proper packing with the monomeric species. The DSC thermogram indicate that high value of glass transition temperature as compared to poly $(\mathrm{N}$ vinylcarbazole) and $\alpha$-methylstyrene. This might have been occurred because high crosslink density and better interpenetration of poly(N-vinylcarbazole) and poly $(\alpha$ methylstyrene). SEM photograph reveals a clear dual phase morphology of polymer network. The fluorescent emission and excitation spectral study of polymeric network depicts emission spectra generation by radioactive decay of excitation which exhibit a maximum peak value at 450 nanometer. This indicates typical high intensity blue light emitting property of the IPN. The synthesized IPN may be applicable in thermal resistant polymers bearing good fluorescent property and photo conducting light emitting diodes.

\section{ACKNOWLEDGMENT}

The authors are gratefull to the Principal, Christ Church P.G. College, Kanpur for providing necessary facilities and also IIT Kanpur for providing SEM, FTIR, Fluorescence and DSC- TGA facilities to carry out the research work.

\section{REFERENCES}

1. Millar JR. J. Chem. Soc., 1960; 311.

2. Sperling LH, Hu R. American Chemical Society, 1994;3-38.
3. Ekici S, Saraydin D. Polym. Int., 2007; 56(11):13711377.

4. Lumelsky Y, Zoldan J, Levenberg S, Silverstein MS. Macromolecules, 2008; 41(4):1469-1474.

5. Zhao X. J. Mech. Phys. Solid, 2012; 60:319-332.

6. Singh A, Meet K, Dhruv KS. J. Int. J. Plast Technol., 2013; 17(2):194-208.

7. Peerasak P, Saraluk S, Sakawrat K, Polym. Int., 2014; 63(6):1041-1046.

8. Prashantha K, Rasmi BJ, Pai KV. Polym. and Polymer Composites, 2015; 23:223.

9. Kyriakos C, Kpameinondas L, Mariliz A, Christina P, Christoforou TK. Polymers, 2016; 8:411.

10. Tamrin SR, Aritonang B. Oriental Journal of chemistry, 2019; 33(4):1994-2003.

11. Singh N, Pandey V, Singh N, Malik MM, Haque FZ. The Optical Society of India, 2017; 1-5.

12. Meet K, Mohd MJ, Singh DK, Shami TC, Baskey HB. J. Advances in Polymer Technology, 2018; 37(7):2663-2673.

13. Petra U, Zagar E, Kovacic S, Pahovnik D. Macromolecules, 2019; 52:819-826.

14. Rui M, Zhao T, Pu H, Sun M, Cui Y, Yie X. ACS Omega, 2020; 5(12):6911-6918.

15. Chatterjee P. Appld. Polym. Sci.J., 1989; 37:2203.

16. Pinner S. Pergamon Press Inc. Tarrytown, N.Y., 1961; 481.

17. Collins EA, Bares J, Billmeyer FW. Jon Wiley and Sons. J. Inc., N.Y., 1973; 481.

18. Xiew H, Ping Z, Xie J, Yu T. J. Polym. Sci. Part A, Polym. Chem., 1990; 2B:5885. 